\title{
MANAJEMEN PEMASARAN SAWI (Brassica Juncea) DI HIDROPONIK CENTER PALEMBANG
}

Marketing Management of Mustard Greens (Brassica Juncea) at The Palembang Hydroponic Center

\author{
${ }^{1}$ Sri Rahayu Endang Lestari \\ ${ }^{1}$ Dosen Jurusan Sosial Ekonomi Program Studi Agribisnis \\ Fakultas Pertanian Universitas Tridinanti Palembang \\ lestarimuhammad@yahoo.com
}

abstract

Based on the research, it can be concluded that, hydroponic vegetable marketing management goes through the stages of planning, implementing, and monitoring the combination of the marketing mix. The product marketing planning stage consists of selecting the type and quantity of products, market surveys, designing marketing strategies and programs. Then implemented into the production process and do marketing. Distribution planning is to determine specific consumers who believe in and accept organic vegetable products. The distribution channel is a short channel, namely from farmers to consumers. Promotion is carried out by socializing through agricultural development fairs and trying internet information technology. The advantages of hydroponic cultivation are:the crop production higher, more controlled pests in plants, faster growth of plants, more efficient use of fertilizers and easier maintenance.

Key words : manajemen pemasaran, sayur sawi, hidroponik

\section{PENDAHULUAN}

Sayuran adalah salah satu komponen dari menu makanan yang sehat, maka tidak heran jika kebutuhan sayuran ini semakin meningkat sejalan dengan kesadaran masyarakat tentang kesehatan. Diantara bermacam - macam jenis sayuran yang dapat dibudidayakan, tanaman sawi (Brassica Juncea)merupakan salah satu komoditas yang mempunyai nilai komersial tinggi ( Margiyanto,
2010). Macam -macam sawi yaitu sawi putih (sawi jagung), sawi hijau (sawi sin), dan sawi huma (sawi pakcoy).

Sawi (Brassica Juncea) merupakan jenis sayur yang digemari oleh masyarakat Indonesia. Konsumennya mulai dari golongan masyarakat kelas bawah hingga golongan masyarakat kelas atas. Kelebihan lainnya sawi mampu tumbuh baik di daratan rendah maupun daratan tinggi. Sawi 
mempunyai nilai ekonomi tinggi setelah kubis krop, kubis bunga, dan brokoli. Tanaman sawi diduga berasal dari Tiongkok (Cina) tanaman ini telah dibudidayakan sejak 2500 tahun lalu, kemudian menyebarluas ke Filipina dan Taiwan.

Tanaman sawi bila ditinjau dari aspek ekonomis dan bisnisnya layak untuk dikembangkan atau diusahakan untuk memenuhi permintaan konsumen serta dan peluang pasar. Kelayakan pengembangan budidaya sawi antara lain ditunjukkan oleh dan banyak keunggulan komparatifkon diwilayah tropis Indonesia yang sangat cocok untuk komoditas tersebut.

Sawi tergolong satu diantara sayuran hijau yang baik bagi kesehatan karena mengandung vitamin dan mineral yang dibutuhkan tubuh. Sejumlah vitamin yang terkandung dalam sawi seperti vitamin B Kompleks dalam bentuk asam folat, vitamin A yang berasal dari karoten, vitamin C, dan vitamin $\mathrm{K}$.

Selain itu, sawi mengandung serat yang cukup tinggi. Semua jenis sawi juga mengandung antioksi dan yang sangat dibutuhkan tubuh. Sawijuga kaya vitamin A dan C cukup tinggi. Semua kandungan tersebut mampu menangkal radikal bebas dan melindungi sel tubuh dari kerusakan. Saking banyaknya kandungan dalam sawi, tak heran sayur ini juga memberikan banyak manfaat bagi kesehatan tubuh.

Sistematika Tanaman Sawi Menurut Haryanto, Suhartini dan Rahayu (2003) adalah sebagai berikut :

Kingdom : Plantae

Divisi : Spermatophyta

Class : Dicotyledonae

Ordo : Rhoeadales

Famili : CruciferaeGenus

Brassica

Spesies $\quad$ : Brassica Juncea L.

Sawi hijau sebagai bahan makanan sayuran mengandung zatzat gizi yang cukup lengkap sehingga apabila dikonsumsi sangat baik untuk mempertahankan kesehatan tubuh. Kandungan gizi setiap $100 \mathrm{~g}$ bahan yang dapat dimakan pada sawi hijau adalah: 
Tabel 1. Kandungan gizi setiap 100 g sawi

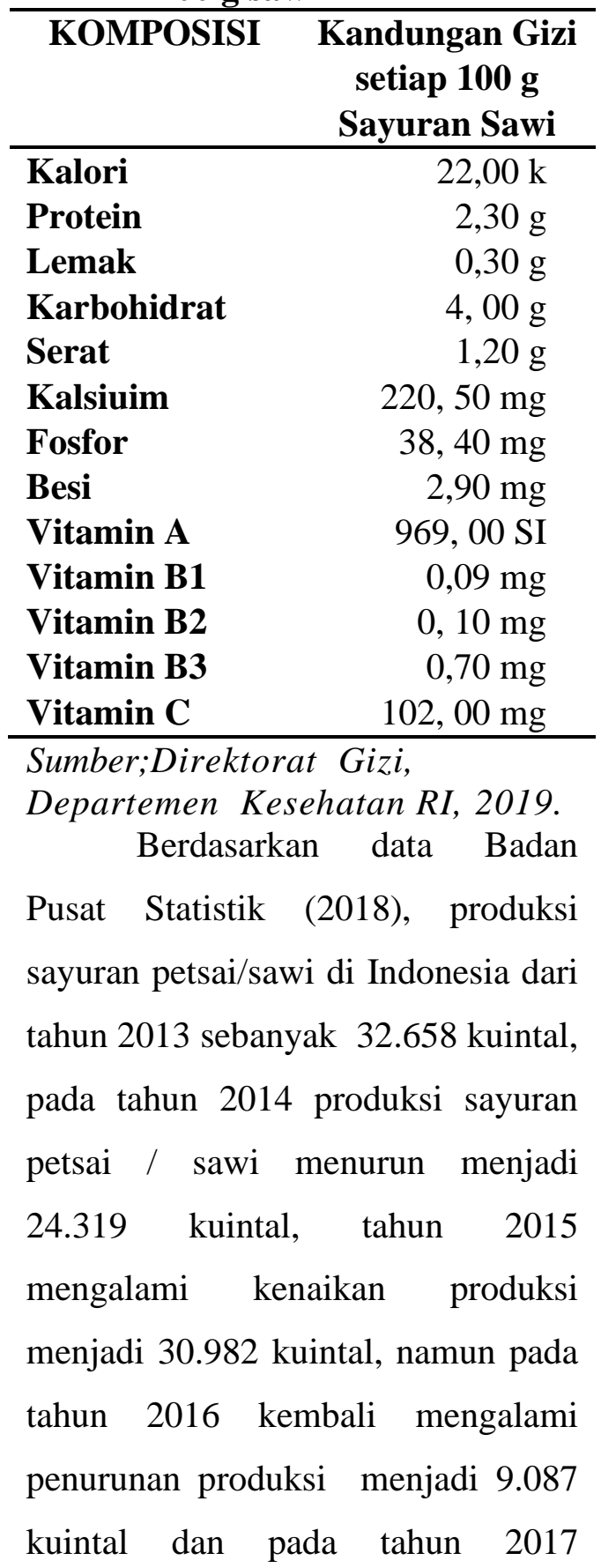

produksi sayuran sawi mengalami kenaikan menjadi 13.234 kuintal.

Munculnya hidroponik didasari keyakinan bahwa tanaman bisa tumbuh dengan baik dimanapun, asalkan kebutuhan nutrisinya (unsure hara) selalu tercukupi. Dalam kontek sini, media selain tanah hanya berperan sebagai penyangga tanaman agar tidak roboh dan air yang memiliki peran penting untuk pertumbuhan tanaman. Air disini bukan air biasa melainkan air dari proes pelarutan nutrisi tanaman yang dibutuhkan (Adam dkk, 2017). Hidroponik merupakan metode bercocok tanam tanpa tanah. Bukan hanya dengan air sebagai media pertumbuhannya, seperti makna lesikal dari kata hidro yang berarti air, tapi juga dapat menggunakan media - media tanamn selain tanah seperti kerikil, pasir, sabut kelapa, zat silikat, pecahan batu karang / batu bata, potongan kayu dan busa (Putri, 2014).

Salah satu sistem hidroponik yaitu NFT (Nutrient Flow Technique) merupakan metode menanam dalam sirkulasi hara tipis pada talang - talang yang 
memanjang. Persemaian biasanya dilakukan diatas rockwool yang dibungkus plastic. Sistem NFT pertama kali diperkenalkan oleh peneliti bernama Dr. Allen Cooper. Sirkulasi larutan hara diperlukan dalam teknologi ini untuk periode waktu tertentu. Hal ini dapat memisahkan komponen lingkungan perakaran yang 'aqueous' dan 'gaeseous' yang dapat meningkatkan serapan hara tanaman (Edukasi, 2018).Adapun rumusan masalah daripenelitian ini adalah untuk mengetahui bagaimana manajemen pemasaran tanaman sawi (Brassica Juncea) di Hidroponik Center Palembang.

\section{METODE PENELITIAN}

\section{Waktu dan Tempat}

Penelitian ini dilaksanakan di Hidroponik Center Palembang selama 1 bulan dimulai pada tanggal 3 Oktober 2020 sampai dengan 3 November 2020.

\section{Metode Penelitian}

Metode penelitian ini dilakukan dengan metode wawancara atau dengan kata lain in-depth interview yang berarti interview yang dilakukan secara langsung dengan pihak manajemen hidroponik center palembang. Selain itu, Metode penelitian dengan cara observasi yaitu metode pengumpulan data yang dilakukan dengan cara pengamatan yang didukung dengan dokumen seperti arsip, foto, kliping, surat dan lain sebagainya.Metode penelitian ini dilakukan jg denganmelihat dan mengamati langsung aktivitas seharihari yang dilakukan selama kegiatan penelitian berlangsung di Hidroponik Center Palembang.

\section{HASIL DAN PEMBAHASAN}

Budidaya tanaman sawi yang dilakukan di Hidroponik Center Palembang menggunakan sistem Nutrient Flow Technique (NFT), sebelum dilakukan kegiatan budidaya tanaman tersebut sebaiknya disiapkan terlebih dahulu alat dan bahan hidroponik, seperti instalasi NFT, larutan nutrisi, benih, media tanam, pompa air dan proses kegiatan budidaya tanaman meliputi : penyemaian, pemeliharaan, panen dan pasca panen. 
1. Persiapan Instalasi Sistem NFT (Nutrient Flow Technique)

Pembuatan instalasi sistem NFT (Nutrient Flow Technique) menggunakan pipa dengan ukuran 2,5 inci dalam satu intalasi yang terdiri dari 6 pipa. Pipa dengan panjang 4 meter.Jumlah pipa yang digunakan dalam satu instalasi sistem NFT sebanyak 6 pipa.Jarak antar pipa adalah 20 $\mathrm{cm}$.

Jarak antar lubang tanam pada pipa adalah $15 \mathrm{~cm}$, dalam 1 pipa terdapat 25 lubang tanam, sehingga dalam 6 pipa terdapat total keseluruhan lubang dalam satu instalasi sitem NFT yang digunakan adalah 150 lubang tanam. Tandon terbuat dari drum plastic berwarna biru yang memiliki kapasitas air sebanyak 200 liter. Tandon dilengkapi pompa air atau water pump berkapasitas 2.000 liter per jam dengan daya 35 watt serta dilengkapi dengan pipa $1 / 2$ inci yang berfungsi untuk mengalirkan air ke dalam pipa instalasi sistem NFT.Tandon diletakkan dengan posisi terguling atau tertidur, hal ini dimaksudkan agar mempermudah saat pengurasan tandon.

\section{Penyemaian Benih}

Benih Sawi (Brassica Juncea) disemai dengan media rockwool yang sudah dipotong dengan ukuran $1 \mathrm{~cm} \times 1 \mathrm{~cm} \times 1$ $\mathrm{cm} \times 1 \mathrm{~cm}$, rockwool disusun dalam nampan plastik kemudian diberi air hingga rockwool menjadi lembab. Media rockwool yang telah lembab diberi lubang tanam kemudian diisikan dengan 2 benih caisim, setelah itu persemaian diletakkan pada tempat yang gelap selama 24 jam hingga berkecambah. Benih yang telah berkecambah kemudian dipindahkan keluar ruangan di rak penyemaian untuk mendapatkan cahaya matahari tetapi tidak terkena hujan.Semaian yang telah berumur 3 hari setelah semai (hss) dipindahkan ke pipa peremajaan dan diberi larutan 
nutrisi $200 \quad$ ppm.Semaian

dipertahankan di pipa peremajaan selama 7 hari setelah semai (hss) dengan jumlah daun sebanyak 5 helai sampai 6 helai.

\section{Penyiapan Larutan Nutrisi}

Gelas ukur dan ember plastik dengan kapasitas 5 liter dipersiapkan sebanyak 2 buah, kemudian air dituangkan sebanyak 5 liter ke dalam masing-masing wadah.Pupuk A dan pupuk B masing-masing dimasukkan ke dalam ember plastik yang telah disediakan dan diaduk hingga larut.Larutan didiamkan selama 30 menit hingga terlarut dengan baik.

Larutan nutrisi mix A mengandung komponen unsur $\mathrm{Ca}, \mathrm{K}$ dan N.Ca berbentuk ion $\mathrm{Ca}++, \mathrm{K}$ berbentuk $\mathrm{K}+$ dan $\mathrm{N}$ berbentuk NO3- (nitrat) dan NH4+ (amonium). Larutan mix B mengandung komponen unsur $\mathrm{Mg}, \quad \mathrm{S}$ dan $\mathrm{P} . \quad \mathrm{Mg}$ berbentuk ion $\mathrm{Mg++}, \mathrm{S}$ berbentuk ion SO4-- dan $\mathrm{P}$ berbentuk ion H2PO4-, HPO4-- atau PO4--- dibuat dari kemasan 5 liter. Pupuk yang digunakan berbentuk cair.

\section{Penanaman}

Tanaman sawi (Brassica Juncea) dipindahkan ke media tanam permanen (modul). Bibit yang telah berumur $7 \mathrm{hst}$ kemudian diseleksi dan pemindahan dilakukan dengan memasukkan bibit beserta rockwool ke dalam netpot. Penanaman menggunakan netpot dilakukan dengan cara memasukkan bibit beserta rockwool ke dalam netpot sehingga akar dapat menyerap larutan nutrisi, kemudian dimasukkan ke dalam lubang tanam.

\section{Penyulaman}

Penyulaman dilakukan apabila ada tanaman yang mati.Penyulaman dilakukan paling lambat 1 minggu setelah penanaman. Bibit yang diambil dari pipa peremajaan sehingga umur tanaman sama. Penyulaman yang terlambat akan menyebabkan pertumbuhan tanaman secara keseluruhan tidak seragam. 
6. Pemberian dan Pengecekan Larutan Nutrisi Nutrisi diberikan dengan cara melarutkan larutan nutrisi mix A sebanyak $500 \mathrm{cc}$ dan larutan mix B sebanyak 500 cc ke dalam tandon atau bak penampungan nutrisi yang berisi 200 liter air. Larutan nutrisi di cek setiap hari dan apabila air larutan berkurang maka segera dilakukan penambahan nutrisi.

\section{Pengecekan TDS/EC Meter}

Pengecekan TDS/EC meter dilakukan pada pagi hari jam 08:00 WIB dan sore hari pukul 16:00 WIB. Pengecekan dilakukan dengan cara memasukkan TDS/EC meter ke dalam larutan pada tandon.

\section{Panen}

Panen dilakukan apabila tanaman sawi telah memiliki ciri-ciri yang sesuai dengan kriteria panen.Kriteria panen yang sesuai didapat apabila daun sudah banyak, daun sawi sudah layak dikonsumsi atau sesuai dengan permintaan pasar, dan apabila tanaman menunjukkan adanya inisiasi pembungaan maka panen dianggap terlambat.

Proses pemanenan dilakukan pada pagi hari atau sore hari antara jam 07:00 WIB sampai dengan jam 08:30 WIB dan pukul 15:30 WIB sampai dengan pukul 16:30 WIB.Pemilihan waktu ini dilakukan karena pada waktu tersebut sinar matahari tidak begitu terik sehingga hasil panen tidak mengalami fluktuasi suhu yang tinggi. Fluktuasi suhu yang tinggi dapat menurunkan kadar air dan kualitas hasil panen secara drastis. Proses pemanenan dilakukan dengan cara mencabut seluruh bagian tanaman bersama akar-akarnya. Satu netpot menghasilkan sayuran sawi dengan bobot kurang lebih 100 gram.Pemanenan dilakukan secara merata pada 1 modul jika pertumbuhan tanaman baik dan merata. Pertumbuhannya jika tidak merata, maka pemanenan dilakukan dengan cara panen 
pilih. Tanaman yang layak dipanen akan segera dipanen, sedangkan tanaman yang tumbuhnya kurang optimal atau rusak akan ditanam ulang atau diganti dengan tanaman yang baru.

\section{Pasca Panen}

Penanganan pasca panen di Hidroponik Center Palembang meliputi :

a) Pengumpulan

Hasil panen ditampung atau dikumpulkan dalam keranjang sterofoam di suatu tempat yang teduh dan bersih.Tujuan pengumpulan produksi ditempat yang teduh dan bersih adalah untuk memudahkan kegiatan penanganan berikutnya dan menekan kerusakan atau susutnya kandungan air pada daun (losses).

b) Pembersihan Tanaman sawi dipisahkan dari netpot dengan cara mencabut tanaman beserta akarnya dari lubang netpot. Akar dibersihkan hingga tidak ada rockwool yang menempel.
Daun-daun yang berwarna kuning dan rusak dibuang dengan cara dipotong.Tanaman sawi yang akarnya telah bersih kemudian daunnya segera dicuci bersih dengan air mengalir, lalu ditiriskan hingga kering.

c) Pengemasan

Sayuran sawi yang telah dibersihkan kemudian ditimbang dengan bobot 250 gram per kemasan.Sayuran sawi yang sudah ditimbang lalu diikat dengan isolasi perekat dan dikemas dalam plastik bening yang telah diberi lubang.Pemberian lubang pada plastik bertujuan untuk menjaga kondisi sayuran agar tidak layu atau busuk.

d) Pemasaran

Pendapatan yang tinggi dari hasil usaha tani selain ditentukan oleh tehnik budidayanya juga ditentukan oleh tehnik pemasarannya. Hal yang perlu diperhatikan dalam pemasaran sawi adalah menentukan standar harga dasar dan pengenalan lembaga 
pemasaran (tata niaga) yang berperan menjual sawi dari petani sampai ke konsumen.Sasaran pasar dari Hidroponik Center Palembang adalah restoran dan pasar modern lainnya.Hidroponik Center Palembang juga menerima pesanan dari warga sekitar dan melayani konsumen yang datang langsung ke tempat.Pemasaran dilakukan setiap hari dengan harga jual yang ditawarkan terhadap pasar untuk sayuran sawi adalah Rp10.000 per 300 gram.

MANAJEMEN PEMASARAN DI HIDROPONIK

\section{PALEMBANG}

1. Manajemen CENTER Sayur Sawi hidroponik

Dilakukan dengan proses menganalisa, merencanakan, mengimplementasika, dan mengawasi semua kegiatan (program) dengan efisien dan efektif sehingga mengacu kepada bauran pemasaran yaitu perencanaan produk, harga, distribusi, dan promosi.

\section{Perencanaan Pemasaran} Sayur Sawi hidroponik

Proses perencanaan produk sayur sawi hidroponik di mulai dengan perencanaan jenis dan jumlah sayur hidroponik yang akan ditanam, survey peluang dan analisis pasar. Selanjutnya agar lebih tepat dan mudah diterima oleh konsumen, maka pemilik usaha akan menetapkan strategi dan membentuk program pemasaran.

\section{Perencanaan Distribusi}

Proses perencanaan distribusi sayur sawi hidroponik adalah menentukan jalan atau rute yang efektif untuk dilalui dalam mengirimkan produk agar sampai ke tangan pelanggan yang sudah pasti memesan produk sayur hidroponik tersebut. Penentuan jalur dan rute yang efektif untuk mempermudah dan melancarkan penyampaian produk tersebut tepat waktu, sehingga nilai unit dan kualitas barang tidak mudah rusak.

\section{Perencanaan Promosi}

Proses perencanaan promosi sayur sawi hidroponik ditentukan berdasarkan bentuk promosi yang akan dipakai adalah pameran pada beberapa 
instansi, dunia pendidikan atau melalui orang perorang yang dikenal dan berkecimpung dibidang pertanian hidroponik khususnya sayur hidroponik.

\section{Implementasi Pemasaran}

Implementasi pemasaran sayur sawi hidroponik merupakan realisasi atau pelaksanaan dari perencanaan produk, perencanaan harga, perencanaan distribusi, dan perencanaan promosi dengan cara mengorganisasi, mengatur dan mengarahkan kegiatan pemasaran sayur sawi hidroponik sehingga diminati oleh konsumen. Bentuk implementasi pemasaran ini berupa realisasi penjualan produk, realisasi kebijakan dan tingkat harga penjualan, realisasi saluran distribusi dan transportasi serta realisasi kegiatan promosi produk sayur hidroponik.

\section{Realisasi penjualan produk}

Realisasi penjualan produk adalah hasil pengaturan dan pengarahan sistem penjualan produk sayur hidroponik kepada konsumen berdasarkan jadwal pemesanan. Hal ini karena sayur hidroponik merupakan produk khusus yang produksi dan pemasarannya harus dipesan konsumen terlebih dahulu, dicatat dan direalisasikan, sehingga berbeda dari sayur konvensional dari sayur konvensional pada umumnya.

\section{Realisasi Kebijakan Harga} dan Tingkat Harga Jual Sayur Hidroponik Center Palembang.

Tahap implementasi

kebijakan atau pengaturan harga produk sayur organik merupakan variabel yang menentukan nilai sayur organik yang dipasarkan sesuai rencana dan merupakan hal penting untuk dikendalikan oleh pengelola atau pengusaha sayur hidroponik dalam mencapai tujuan penjualan produk yang menguntungkan.

8. Kendala - Kendala Manajemen Pemasaran Sayur Hidroponik.

Kendala yang ditemui yaitu belum dapat bersaing di pasar tradisional.Kendala pada harga adalah konsumen pasar 


\begin{abstract}
tradisional belum dapat menerima harga sayur hidroponik yang mahal, karena pengetahuan masyarakat belum sampai tentang manfaat sayur hidroponik.Sehingga kendala yang dihadapi pada distribusi adalah keterbatasan jumlah konsumen karena faktor harga yang mahal. Kendala lainnya adalah sistem penyimpanan produk sayur hidroponik saat selesai panen masih sederhana tanpa ada lemari penyimpanan modern yang khusus.
\end{abstract}

\section{KESIMPULAN DAN SARAN}

\section{Kesimpulan}

Berdasarkan pembahasan yang telah diuraikan di atas, maka dapat disimpulkan bahwa, Manajemen pemasaran sayur hidroponik melalui tahap merencanakan, mengimplementasikan, dan mengawasi kombinasi dari bauran pemasaran. Tahap perencanaan pemasaran produk terdiri dari pemilihan jenis dan jumlah produk, survey pasar, merancang strategi dan program pemasaran. Kemudian diimplementasikan kedalam proses produksi dan melakukan pemasaran. Perencanaan distribusi adalah menentukan konsumen khusus yang percaya dan menerima produk sayur organik. Saluran distribusinya adalah saluran pendek yaitu dari petani kepada konsumen. Promosi dilakukan dengan mensosialisaikan melalui pameran pembangunan pertanian dan mencoba teknologi informasi internet. Keuntungan dari budi daya tanaman secara hidroponik yaitu produksi tanaman lebih tinggi, hama pada tanaman lebih terkendali, tanaman tumbuh lebih cepat, pemakaian pupuk lebih hemat dan mudah dalam pemeliharaan.

\section{Saran}

Adapun saran yang dapat penulis berikan yakni di era modern dalam menghadapi persaingan pemasaran, penentuan strategi pemasaran sangat penting dan hal ini juga harus di tunjang oleh manajemen pemasaran yang memiliki kreativitas yang tinggi. Jadi sebaiknya tempatkanlah manajemen pemasaran sebagai 
bagian penting demi mencapai tujuan bisnis dengan profitabilitas yang tinggi.

\section{DAFTAR PUSTAKA}

Adam, A., Rumengan I., dan Tallei, T. 2017. Hidroponik Untuk Pemula. Penerbit LPPM UNSRAT Manado.

Anonim. 2017. Budidaya Tanaman Sawi.Diaksesdarihttp://opiwarn etcipayung.blogspot.com/2017/ 01/budidaya-tanamansawi.htmlpada tanggal 25 Oktober 2019.

Badan Pusat Statistik. 2018. Produksi Tanaman Sawi di Indonesia. Diakses dari http://respository.ub.ac.id/1234 4 pada tanggal 27 Oktober 2019.

Edukasi, S. 2018. Buku Hidroponik. Diakses dari http://www.berkasedukasi.com /2018/09/buku-hidroponik-pdfgratis.html pada tanggal 27 Oktober 2019.

Kamsa, A. 2019. Panduan Sederhana Belajar Hidroponik. Palembang.

Margiyanto, E. 2008. Budidaya Tanaman Sawi. Diakses dari http://zuldesain.wordpress.com pada tanggal 31 Oktober 2019.

Putri, N. 2014.Laporan Hasil Praktek Bio Teknologi Modern Hidroponik. Diakses dari http://bnetpwj.blogspot.com/20 14/12/makalahhidroponik.html pada tanggal31 Oktober 2019.

Rukmana, R. 1994. Bertanam Petsai dan Sawi.Kanisius. Yogyakarta. 


\section{Saran}

Adapun saran yang dapat penulis berikan yakni di era modern dalam menghadapi persaingan pemasaran, penentuan strategi pemasaran sangat penting dan hal ini juga harus di tunjang oleh manajemen pemasaran yang memiliki kreativitas yang tinggi. Jadi sebaiknya tempatkanlah manajemen pemasaran sebagai bagian penting demi mencapai tujuan bisnis dengan profitabilitas yang tinggi.

\section{DAFTAR PUSTAKA}

Adam, A., Rumengan I., dan Tallei, T. 2017. Hidroponik Untuk Pemula. Penerbit LPPM UNSRAT Manado.

Anonim. 2017. Budidaya Tanaman Sawi. Diakses darihttp://opiwarnetcipayung. blogspot.com/2017/01/budidaya-tanaman-sawi.htmlpada tanggal 25 Oktober 2019.

Badan Pusat Statistik. 2018. Produksi Tanaman Sawi di Indonesia. Diakses dari http://respository.ub.ac.id/12344 pada tanggal 27 Oktober 2019.

Edukasi, S. 2018. Buku Hidroponik. Diakses dari http://www.berkasedukasi.com/ 2018/09/buku-hidroponik-pdf-gratis.html pada tanggal 27 Oktober 2019.

Kamsa, A. 2019. Panduan Sederhana Belajar Hidroponik. Palembang.

Margiyanto, E. 2008. Budidaya Tanaman Sawi. Diakses dari http://zuldesain.word press.com pada tanggal 31 Oktober 2019.

Putri, N. 2014.Laporan Hasil Praktek Bio Teknologi Modern Hidroponik. Diakses dari http://bnetpwj.blogspot.com/2014/12/makalah-hidroponik.html pada tanggal31 Oktober 2019.

Rukmana, R. 1994. Bertanam Petsai dan Sawi.Kanisius.Yogyakarta. 
ISSN No 2086-7956 E-ISSN No 2615-5494

Jurnal AGRIBIS Vol 14. No. 1 Januari 2021 Hal 1635-1649 